\title{
Comparison of the Effects of Ketamine-Dexmedetomidine and Sevoflurane-Sufentanil Anesthesia on Cardiac Biomarkers After Cardiac Surgery: An Observational Study
}

\author{
H. ŘÍHA ${ }^{1,2}$, T. KOTULÁK ${ }^{1}$, A. BŘEZINA ${ }^{1}$, L. HESS $^{3}$, P. KRAMÁŘ ${ }^{1}$, O. SZÁRSZOI ${ }^{2,4}$, \\ I. NETUKA ${ }^{2,4}$, J. PIRK ${ }^{2,4}$ \\ ${ }^{1}$ Department of Anesthesiology and Intensive Care Medicine, Institute for Clinical and \\ Experimental Medicine, Prague, Czech Republic, ${ }^{2}$ Centre for Cardiovascular Research, Prague, \\ Czech Republic, ${ }^{3}$ Centre for Experimental Medicine, Institute for Clinical and Experimental \\ Medicine, Prague, Czech Republic, ${ }^{4}$ Department of Cardiovascular Surgery, Institute for Clinical \\ and Experimental Medicine, Prague, Czech Republic
}

Received May 11, 2011

Accepted November 22, 2011

On-line December 20, 2011

\section{Summary}

Inhalational anesthetics have demonstrated cardioprotective effects against myocardial ischemia-reperfusion injury. Clinical studies in cardiac surgery have supported these findings, although not with the consistency demonstrated in experimental studies. Recent investigations have questioned the advantages of inhalational over intravenous anesthetics with respect to cardiac protection. Ketamine has been shown to be comparable with sufentanil, and has even demonstrated anti-inflammatory properties. Dexmedetomidine has been established as a sedative/anesthetic drug with analgesic properties, and has also demonstrated myocardial protective effects. In this retrospective observational study, the influence of ketamine-dexmedetomidinebased anesthesia (KET-DEX group; $n=17$ ) on the release of cardiac biomarkers was compared with that of sevofluranesufentanil-based anesthesia (SEVO group; $n=21$ ) in patients undergoing elective coronary artery bypass grafting. Compared with the SEVO group, the KET-DEX group exhibited significantly reduced cardiac troponin I $(2.22 \pm 1.73$ vs. $3.63 \pm 2.37 \mu \mathrm{g} / \mathrm{l}$; $P=0.02$ ) and myocardial fraction of creatine kinase (CK-MB) levels (12.4 \pm 10.4 vs. $20.3 \pm 11.2 \mu \mathrm{g} / \mathrm{l} ; P=0.01)$ on the morning of the first postoperative day. Furthermore, cardiac troponin I release, evaluated as the area under the curve, was significantly reduced in the KET-DEX group $(32.1 \pm 20.1$ vs. $50.6 \pm 23.2$; $P=0.01)$. These results demonstrate the cardioprotective effects of ketamine-dexmedetomidine anesthesia compared with those of sevoflurane-sufentanil anesthesia.

\section{Key words}

Myocardial ischemia-reperfusion injury - Ketamine • Dexmedetomidine • Sevoflurane • Cardiac troponin I

\section{Corresponding author}

Hynek Riha, Department of Anesthesiology and Intensive Care Medicine, Institute for Clinical and Experimental Medicine, Videnska 1958/9, Prague 140 21, Czech Republic. Fax: +42026136 2799. E-mail: hynek.riha@ikem.cz

\section{Introduction}

Inhalational anesthetics have been reported to exhibit cardioprotective effects against myocardial ischemia-reperfusion injury in a number of animal experiments (De Hert et al. 2009). Subsequent clinical studies involving cardiac surgical patients have supported these findings, although not with the consistency demonstrated in experimental studies (Landoni et al. 2009). The first clinical study describing the use of preconditioning with isoflurane in coronary artery bypass grafting $(\mathrm{CABG})$ demonstrated reduced postoperative levels of cardiac troponin I (cTnI) and a decreased myocardial fraction of creatine kinase (CK-MB) (Belhomme et al. 1999). A meta-analysis of 22 cardiac surgical studies indicated that the inhalational anesthetics sevoflurane and desflurane were associated with reduced 
rates of morbidity and mortality compared with total intravenous anesthesia (TIVA) (Landoni et al. 2007). However, a recent study failed to demonstrate the difference between isoflurane-opioid and propofol-opioid anesthesia in CABG patients with regard to postoperative cTnI release (Flier et al. 2010).

Ketamine is a dissociative sedative-hypnotic drug with potent analgesic properties and marked sympathomimetic effects on the cardiovascular system (Craven 2007). Recently, S-(+)-ketamine has been demonstrated to be a safe analgesic drug compared with sufentanil during CABG in adult patients, as determined by hemodynamic stability and cardiac troponin $\mathrm{T}$ (cTnT) release (Neuhauser et al. 2008). Dexmedetomidine is a highly selective, short-acting, central $\alpha_{2}$-adrenergic agonist with intense sympatholytic qualities. Dexmedetomidine has been increasingly used as a component of general anesthesia, including cardiac surgical applications (Jalonen et al. 1997) due to its sedative/hypnotic and analgesic effects (Easley and Tobias 2008), which are enhanced by its cardioprotective properties (Aantaa and Jalonen 2006).

We hypothesized that, compared with anesthesia using inhalational anesthetics with opioids, TIVA using ketamine-dexmedetomidine would be accompanied by a marked cardioprotective effect. Accordingly, the primary objective of this study was to compare the effect of ketamine-dexmedetomidine-based anesthesia with that of sevoflurane-sufentanil-based anesthesia on the release of cardiac biomarkers after CABG. An additional aim of the study was to compare intraoperative and postoperative clinical markers of myocardial injury in patients treated with these two anesthetic regimens.

\section{Methods}

\section{Patient population}

We retrospectively identified patients in our institution who received TIVA with ketamine and dexmedetomidine from a group of patients who underwent elective $\mathrm{CABG}$ procedures with the use of cardiopulmonary bypass (CPB) to treat coronary artery disease between January and September 2010. The control group was comprised of patients who underwent elective $\mathrm{CABG}$ during the same time period and received sevoflurane-sufentanil anesthesia and presented with essentially the same preoperative and intraoperative characteristics, i.e., age $\leq 75$ years, left ventricular ejection fraction $(\mathrm{LVEF}) \geq 45 \%$, normal preoperative
cTnI level, glomerular filtration rate (estimated by the Modification of Diet in Renal Diseases [MDRD] equation) $>1.0 \mathrm{ml} / \mathrm{s} / 1.73 \mathrm{~m}^{2}$ and intraoperative use of crystalloid cardioplegic solution for myocardial protection.

All patients provided full, written informed consent for general anesthesia before surgery. Approval for this retrospective observational study was granted by the local ethics committee.

\section{Cardiac surgery}

The CABG procedures were performed by consultant-level surgeons who employed the midline sternotomy approach. The left internal mammary artery was harvested in all cases. The CPB circuit was primed with $1000 \mathrm{ml}$ of Ringer's solution with $250 \mathrm{ml}$ of $20 \%$ mannitol. A non-pulsatile blood flow of $2.4 \mathrm{l} / \mathrm{min} / \mathrm{m}^{2}$ was established using a membrane oxygenator, with perfusion pressure maintained at between 45 and $70 \mathrm{~mm} \mathrm{Hg}$. Cardiac arrest and myocardial protection were obtained through the administration of cold crystalloid cardioplegic solution (St. Thomas). Patients were cooled to $34{ }^{\circ} \mathrm{C}$ applying $\alpha$-stat acid-base management.

\section{Anesthesia and intensive care}

On the day of surgery, all patients received preoperative cardiac medication, with the exception of angiotensin-converting enzyme inhibitors, angiotensin II antagonists and diuretics. Oral antidiabetic drugs were also omitted. Premedication consisted of an oral dose of $7.5 \mathrm{mg}$ of midazolam $(3.75 \mathrm{mg}$ in patients with body weight $<65 \mathrm{~kg}$ ). All of the patients received general anesthesia with endotracheal intubation facilitated by intravenous cis-atracurium at a dose of $0.2 \mathrm{mg} / \mathrm{kg}$; neuromuscular blockade throughout surgery was achieved by the continuous infusion of cis-atracurium at a rate of $2 \mu \mathrm{g} / \mathrm{kg} / \mathrm{min}$. Volume-controlled mechanical ventilation with oxygen in the air (fraction of inspired oxygen $=0.5$ ) and a positive end-expiratory pressure of $5 \mathrm{~cm} \mathrm{H}_{2} \mathrm{O}$ was targeted to an end-tidal carbon dioxide level of $35 \mathrm{~mm} \mathrm{Hg}$. Corticosteroids were not administered to any patients throughout the perioperative period.

Anesthesia in patients receiving combination ketamine-dexmedetomidine was induced by intravenous midazolam $(0.1 \mathrm{mg} / \mathrm{kg})$ and dexmedetomidine $(1 \mu \mathrm{g} / \mathrm{kg}$ over $10 \mathrm{~min})$, followed by ketamine $(1-2 \mathrm{mg} / \mathrm{kg})$. Sufentanil (0.15-0.25 $\mu \mathrm{g} / \mathrm{kg})$ was administered, as needed, before the skin incision was made and before 
cannulation for CPB. Anesthesia was maintained through the continuous infusion of ketamine at a rate of $2-4 \mathrm{mg} / \mathrm{kg} / \mathrm{h}$, which was decreased to $2 \mathrm{mg} / \mathrm{kg} / \mathrm{h}$ after CPB and terminated 20-30 min before the end of surgery. Dexmedetomidine was infused at a rate of $0.5-1.5 \mu \mathrm{g} / \mathrm{kg} / \mathrm{h}$; midazolam $(0.1 \mathrm{mg} / \mathrm{kg})$ was added at the commencement of CPB.

Sevoflurane-sufentanil anesthesia was induced by intravenous administration of midazolam $(0.05 \mathrm{mg} / \mathrm{kg})$, sufentanil $(0.5 \mu \mathrm{g} / \mathrm{kg})$ and etomidate $(0.2 \mathrm{mg} / \mathrm{kg})$. The anesthesia was maintained with sevoflurane (1.0-1.5 MAC end-tidal) during the entire surgical procedure (during $\mathrm{CPB}$, sevoflurane was administered through the oxygenator of the CPB circuit) and with continuous infusion of sufentanil at a rate of $0.4-0.8 \mu \mathrm{g} / \mathrm{kg} / \mathrm{h}$; midazolam $(0.05 \mathrm{mg} / \mathrm{kg})$ was added at the commencement of CPB.

Following surgery, the patients were transported to the cardiothoracic surgical intensive care unit (ICU). Adhering to a fast-track protocol, standardized intensive care was implemented, and analgesia was provided by intravenous morphine, ketoprofen and paracetamol. Extubation was performed in circulatory-stable patients after a period of gradual weaning from mechanical ventilatory support. Control of blood glucose level was achieved through continuous insulin infusion, maintaining a glycemic range of 5.5-8.0 $\mathrm{mmol} / \mathrm{l}$.

\section{Blood sampling and biochemical analysis}

Adhering to stadardized protocols mandated by departmental guidelines (i.e., at the patient's arrival in the ICU and on the morning of the first postoperative day), blood samples for biochemical analysis were extracted from all patients. The time interval between the end of myocardial ischemia (i.e., the release of the aortic crossclamp with the initiation of myocardial reperfusion) and the extraction of blood samples for the measurement of cardiac biomarkers was recorded. In addition to obtaining two measures of cTnI levels, the overall release of this biomarker was evaluated using the area under the curve (AUC).

The plasma concentrations of cTnI and CK-MB (mass) were determined using commercially available chemiluminescent microparticle immunoassays and an automated analyzer (ARCHITECT STAT Troponin-I and CK-MB; Abbott Laboratories, Diagnostics Division, Abbott Park, IL, USA). The reference range for cTnI is $0.0-0.03 \mu \mathrm{g} / 1$ (with an analytical sensitivity $\leq 0.01 \mu \mathrm{g} / \mathrm{l}$ at a $95 \%$ level of confidence); the reference range for $\mathrm{CK}$ -
MB (mass) is $0.0-7.2 \mu \mathrm{g} / \mathrm{l}$ (with an analytical sensitivity $\leq 0.1 \mu \mathrm{g} / \mathrm{l}$ at a $95 \%$ level of confidence).

\section{Statistics}

Continuous variables are expressed as mean \pm standard deviation and were compared using the Student's t-test. Non-parametric continuous variables are expressed as medians with interquartile range, and compared using the Mann-Whitney $U$ test. Testing for data normality was conducted using the KolmogorovSmirnov goodness-of-fit test. Fisher's exact test was used for comparisons of categorical variables. All hypothesis testing was two-tailed, and differences were considered to be statistically significant at $P<0.05$. All statistical analyses were performed using GraphPad Prism version 5.04 software for Windows (GraphPad Software, San Diego, CA, USA).

\section{Results}

\section{Patient population}

Patients receiving ketamine-dexmedetomidine anesthesia constituted the study group (KET-DEX group; $n=17$ ). The control group consisted of patients receiving sevoflurane-sufentanil anesthesia (SEVO group; $n=21$ ). One patient was excluded from the control group due to electrocardiographic indications of postoperative myocardial ischemia upon arrival in the ICU, which required immediate coronary angiography with subsequent re-operation.

The patients did not differ with respect to baseline preoperative characteristics (Table 1). Both groups were comprised of low-risk patients, with maximal values of 5.9 on the logistic EuroSCORE for the KET-DEX group and 6.3 for the SEVO group.

\section{Intraoperative data}

No significant differences in important intraoperative data between the two groups were observed (Table 2). The number of patients who required short-term, low-dose nitroglycerine infusion due to hypertension at the beginning of surgery demonstrated a non-significant trend of higher incidence in the KETDEX group $(P=0.43)$. One patient in the KET-DEX group developed severe bradycardia $(\leq 50 / \mathrm{min})$ after anesthesia induction, which required atropine $(0.5 \mathrm{mg})$ administration $(5.9 \%$ in the KET-DEX group vs. $0 \%$ in the SEVO group; $P=0.45)$. There was no difference in the number of direct, low-energy, biphasic defibrillation 
discharges (with a cumulative energy $\leq 25 \mathrm{~J}$ ) required after unclamping of the aorta between groups $(P=0.48)$; the same finding was observed for the number of patients who did not require discharge $(35.3 \%$ in the KET-DEX group vs. $19.1 \%$ in the SEVO group; $P=0.29$ ).

Table 1. Patients' baseline preoperative characteristics.

\begin{tabular}{lcc}
\hline Parameter & $\begin{array}{c}\text { Sevoflurane-sufentanil } \\
(\mathbf{n = 2 1 )}\end{array}$ & $\begin{array}{c}\text { Ketamine-dexmedetomidine } \\
\text { (n = 17) }\end{array}$ \\
\hline Age (years) & $66.5 \pm 7.4$ & $62.9 \pm 8.7$ \\
Sex $(M / F$ [\%]) & $81.0 / 19.0$ & $88.2 / 11.8$ \\
BMI (kg/m) & $29.3 \pm 4.1$ & $28.8 \pm 4.8$ \\
Hypertension (\%) & 57.1 & 64.7 \\
MI (\%) & 52.4 & 58.8 \\
LVEF (\%) & $56 \pm 7$ & $59 \pm 9$ \\
GFR (ml/s) & $1.35 \pm 0.29$ & $1.25 \pm 0.25$ \\
Chronic cardiovascular medication & & 81.0 \\
Beta-blockers (\%) & 82.4 & 35.3 \\
Calcium channel blockers (\%) & 28.6 & 47.1 \\
ACEIs (\%) & 52.4 & 23.5 \\
Loop diuretics (\%) & 19.1 & 88.2 \\
Statins (\%) & 81.0 & 29.4 \\
Diabetes mellitus (\%) & 33.3 & 11.8 \\
- Insulin (\%) & 9.5 & 17.6 \\
- Oral antidiabetics (\%) & 23.8 & 5.9 \\
- Sulfonylurea derivatives (\%) & 9.5 & $(1.2-3.2)$ \\
Logistic EuroSCORE & $2.1(1.3-3.9)$ & \\
\hline
\end{tabular}

Values are presented as mean $\pm S D$ or median (interquartile range) unless otherwise indicated. $n$, number of patients; $M$, male sex; F, female sex; BMI, body mass index; MI, myocardial infarction in medical history; LVEF, left ventricular ejection fraction; ACEIs, angiotensin-converting enzyme inhibitors; GFR, glomerular filtration rate estimated by the MDRD (The Modification of Diet in Renal Diseases) equation; EuroSCORE, European System for Cardiac Operation Risk Evaluation.

Table 2. Important intraoperative data.

\begin{tabular}{lcc}
\hline Parameter & $\begin{array}{c}\text { Sevoflurane-sufentanil } \\
(\mathbf{n = 2 1 )}\end{array}$ & $\begin{array}{c}\text { Ketamine-dexmedetomidine } \\
(\mathbf{n}=\mathbf{1 7})\end{array}$ \\
\hline NTG infusion before CPB (\%) & 14.3 & 29.4 \\
Duration of CPB (min) & $71.0 \pm 18.7$ & $74.4 \pm 13.5$ \\
Duration of AXC (min) & $42.4 \pm 14.3$ & $41.5 \pm 12.1$ \\
Number of grafts & $4(3-4)$ & $3(3-4)$ \\
Number of delivered biphasic & $1(1.0-1.5)$ & $1(0-1.5)$ \\
defibrillation discharges & 14.3 & 11.8 \\
Inotropes after CPB (\%) & 19.1 & 23.5 \\
Use of pacing after CPB (\%) & &
\end{tabular}

Values are presented as mean \pm SD or median (interquartile range) unless otherwise indicated. $n$, number of patients; NTG, nitroglycerin; CPB, cadiopulmonary bypass; AXC, aortic cross-clamping. 
Table 3. Postoperative clinical course.

\begin{tabular}{lcc}
\hline Parameter & $\begin{array}{c}\text { Sevoflurane-sufentanil } \\
(\mathbf{n = 2 1 )}\end{array}$ & $\begin{array}{c}\text { Ketamine-dexmedetomidine } \\
(\mathbf{n}=\mathbf{1 7})\end{array}$ \\
\hline Length of stay in ICU $(h)$ & $22.8(21.8-23.2)$ & $23.5(18.2-25.9)$ \\
Time to extubation $(h)$ & $8.3 \pm 2.1$ & $6.8 \pm 2.2^{*}$ \\
Inotropes (\%) & 9.5 & 5.9 \\
Vasopressors (\%) & 19.0 & 17.7 \\
Pacing (\%) & 14.3 & 11.8 \\
Atrial fibrillation in ICU (\%) & 19.0 & 23.5 \\
Atrial fibrillation in hospital (\%) & 33.3 & 29.4 \\
30-day mortality (\%) & 0.0 & 0.0 \\
\hline
\end{tabular}

Values are presented as mean $\pm S D$ or median (interquartile range) unless otherwise indicated. ${ }^{*} P<0.05$ vs. the sevoflurane-sufentanil group. $n$, number of patients; ICU, cardiothoracic surgical intensive care unit.

\section{Clinical postoperative data}

Table 3 summarizes the important postoperative clinical parameters that were examined during patients' stays in the hospital. Transient $(\leq 6 \mathrm{~h})$, inotropic (dobutamine $\leq 5 \mu \mathrm{g} / \mathrm{kg} / \mathrm{min}$ ) and vasopressor (norepinephrine $\leq 0.1 \mu \mathrm{g} / \mathrm{kg} / \mathrm{min}$ ) support was required by a similar number of patients in both groups. The same finding was observed for transient ventricular pacing, which was emloyed in the ICU in cases of low heart rate $(<60 / \mathrm{min})$. During stays in the ICU, no patients experienced postoperative agitation or confusion. Review of the patients' medical charts to investigate this phenomenon during the four days after transport of patients from the ICU to the high-dependency cardiac surgical unit indicated that one patient in each group (5.9\% vs. $4.8 \% ; P=1.0$ ) experienced transient agitation, which resolved spontaneously. No major complications were noted in either group, and no patients died during the 30 days following surgery.

\section{Cardiac biomarkers and other laboratory parameters}

The time intervals between the release of the aortic cross-clamp at the initiation of myocardial reperfusion and the collection of blood samples for the measurement of cardiac biomarkers did not differ between the KET-DEX and SEVO groups: $114.2 \pm 15.4$ vs. $122.3 \pm 16.8 \mathrm{~min}(P=0.14)$ for the measurements taken at the patients' arrival in the ICU, and $1140.0 \pm 47.2$ vs. $1154.0 \pm 42.9 \mathrm{~min}(P=0.33)$ for the measurements taken on the morning of the first postoperative day. There were no significant differences in the plasma concentrations of cardiac biomarkers at the patients' arrival in the ICU ( $P=0.07$ for $\mathrm{cTnI}$ and $P=0.19$ for CK-MB). On the morning of the first postoperative day, the patients in the KET-DEX group exhibited significantly decreased plasma concentrations of $\mathrm{cTnI}(P=0.02)$ and CK-MB $(P=0.01)$ (Fig. 1 and 2). For overall cTnI release, the AUC is displayed in Fig. 3, which illustrates a significantly smaller area for the KET-DEX group $(P=0.01)$.

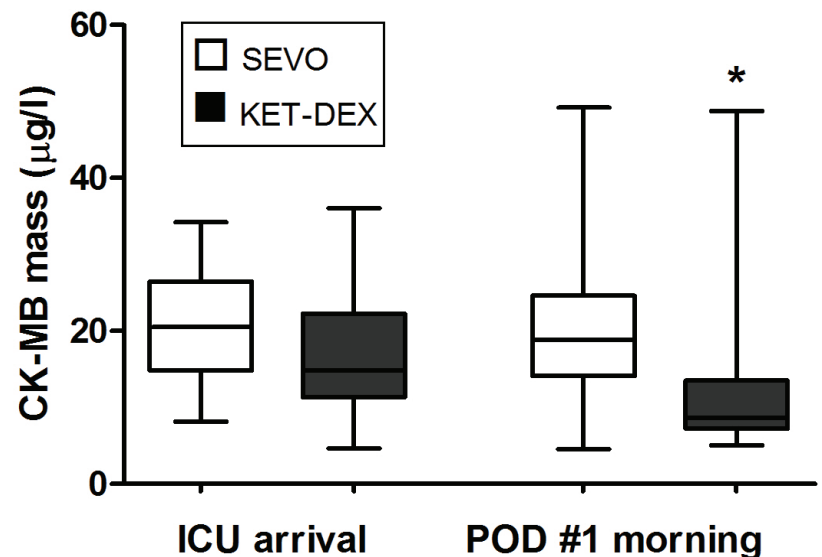

Fig. 1. Effects of ketamine-dexmedetomidine (KET-DEX) compared with those of sevoflurane-sufentanil (SEVO) anesthesia on the myocardial fraction of creatine kinase (CK-MB) release at the time of arrival in the intensive care unit (ICU) and on the morning of the first postoperative day (POD) after cardiac surgery. Values are presented as medians with interquantile ranges and minimum and maximum values. ${ }^{*} P<0.05$ vs. the SEVO group.

Lactate levels, which were measured at the patients' arrival in the ICU $(1.4 \pm 0.3$ vs. $1.4 \pm 0.5 \mathrm{mmol} / \mathrm{l}$; $P=0.69)$, at the time of extubation $(1.3 \pm 0.4$ vs. $1.2 \pm 0.4$ $\mathrm{mmol} / \mathrm{l} ; \quad P=0.76$ ) and on the morning of the first postoperative day ( $1.3 \pm 0.3$ vs. $1.2 \pm 0.3 \mathrm{mmol} / \mathrm{l} ; P=0.40)$, 
were similar between the KET-DEX and SEVO groups. Laboratory markers of liver function that were evaluated on the morning of the first postoperative day were comparable between the two groups: total bilirubin (11.6 [9.0-15.8] vs. $14.2[10.7-20.5] ; \quad P=0.17)$, aspartate aminotransferase $(0.85 \pm 0.23$ vs. $1.0 \pm 0.27 \mu \mathrm{kat} / \mathrm{l} ; P=0.08)$ and alanine aminotransferase $(0.50[0.40-0.64]$ vs. 0.64 [0.40-0.87]; $P=0.28)$. The glomerular filtration rate, estimated by the MDRD equation, was also comparable between the two groups $(1.26 \pm 0.33$ vs. $1.33 \pm 0.39 \mathrm{ml} / \mathrm{s} / 1.73 \mathrm{~m}^{2} ; P=0.60$ ). For white blood cell counts obtained on the morning after surgery, a nonsignificant difference between the two groups was observed (11.5 2.6 vs. $\left.13.3 \pm 3.1 * 10^{9} / 1 ; P=0.06\right)$.

\section{Discussion}

The primary findings of the present study are the significantly lower plasma cTnI and CK-MB concentrations on the morning after surgery, which were accompanied by a significantly lower overall cTnI release after elective $\mathrm{CABG}$ in the patients who received ketamine-dexmedetomidine anesthesia compared with sevoflurane-sufentanil anesthesia. Furthermore, patients receiving ketamine-dexmedetomidine anesthesia demonstrated a trend toward lower white blood cell counts following surgery. To the best of our knowledge, the present study is the first to demonstrate cardioprotective properties of ketamine-dexmedetomidine anesthesia.

Inhalational anesthetics in cardiac surgery have been demonstrated to be associated with beneficial effects on biochemical markers of myocardial injury (Belhomme et al. 1999) and functional hemodynamic parameters (De Hert et al. 2002). Furthermore, published results of a survey of 64 cardiac surgical centres indicated a significantly reduced risk-adjusted rate of mortality associated with the use of inhalational anesthetics (Bignami et al. 2009). However, the cardioprotective effects of inhalational anesthetics can vary depending on the timing of their administration. Sevoflurane was reported to be associated with lower levels of postoperative cTnI release and enhanced preservation of myocardial function when administered throughout the surgical procedure (De Hert et al. 2004). Two cycles of sevoflurane administration, in addition to TIVA, were demonstrated to significantly reduce cTnI levels compared with one cycle of sevoflurane (Frassdorf et al. 2009). For these reasons, we administered sevoflurane throughout the cardiac surgical procedures, including $\mathrm{CPB}$.

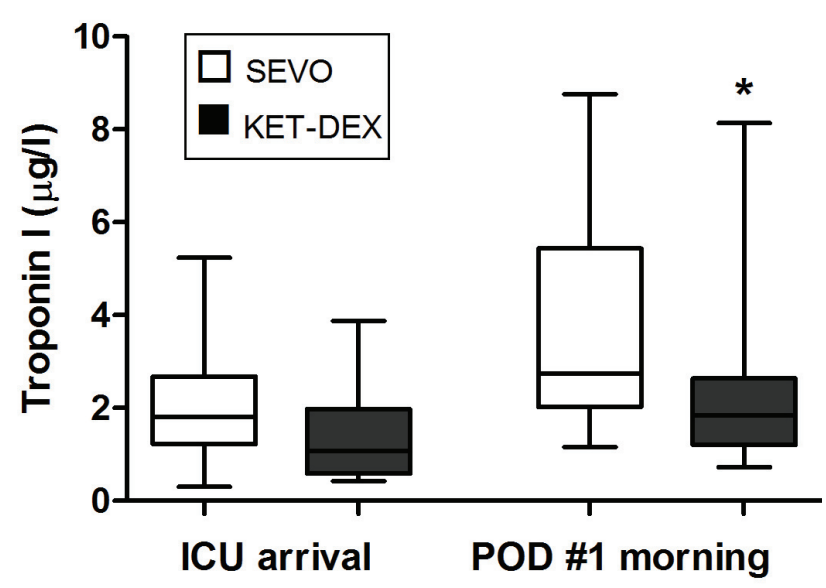

Fig. 2. Effects of ketamine-dexmedetomidine (KET-DEX) compared with those of sevoflurane-sufentanil (SEVO) anesthesia on the release of troponin I at the time of arrival in the intensive care unit (ICU) and on the morning of the first postoperative day (POD) after cardiac surgery. Values are presented as medians with interquantile ranges and minimum and maximum values. ${ }^{*} P<0.05$ vs. the SEVO group.

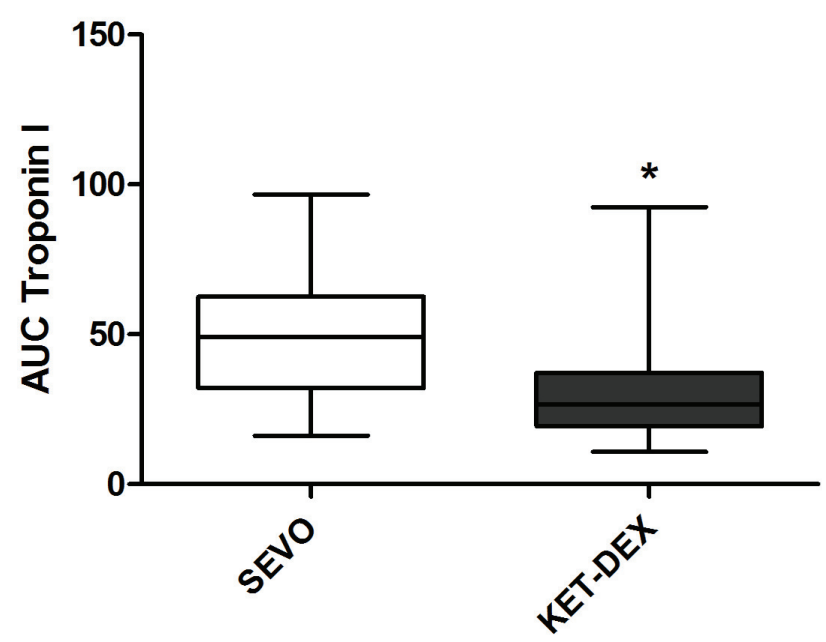

Fig. 3. Area under the curve (AUC) of troponin I values on the morning of the first day after cardiac surgery emloying ketaminedexmedetomidine (KET-DEX) or sevoflurane-sufentanil (SEVO) anesthesia. Values are presented as medians with interquantile ranges and minimum and maximum values. ${ }^{*} P<0.05$ vs. the SEVO group.

Among the intravenous anesthetics, propofol, which is widely employed, exhibited anti-oxidant properties (Murphy et al. 1992). Compared with isoflurane, the use of high-dose propofol during CPB led to reduced levels of cTnI, cTnT and CK-MB in patients undergoing CABG (Xia et al. 2006). Conversely, compared with isoflurane, normal doses of propofol did not produce altered cTnI levels (Flier et al. 2010, Xia et al. 2006).

Ketamine has not been employed frequently in 
cardiac surgery due to central sympathetic stimulation that overrides its direct myocardial depressant effect (Craven 2007). Recently, a bolus of racemic ketamine administered during the induction of general anesthesia was reported to cause a decrease in the incidence of postoperative delirium and to reduce the levels of C-reactive protein after cardiac surgery, suggesting an anti-inflammatory effect (Hudetz et al. 2009). Furthermore, S-(+)-ketamine - one of two enantiomers of a racemic mixture of ketamine - administrated during CABG as a component of TIVA, instead of sufentanil, has been demonstrated to significantly attenuate the proinflammatory cytokine response, reducing the levels of interleukin (IL)-6 and IL-8 (Welters et al. 2011), and has also been observed to induce comparable cTnT levels (lower levels were only reported at $6 \mathrm{~h}$ after aortic unclamping, but not after $24 \mathrm{~h}$ ) (Neuhauser et al. 2008). However, racemic ketamine, which is widely available in the form employed in the present study, was reported to inhibit ischemic preconditioning in vivo (Mullenheim et al. 2001) by inhibiting sarcolemmal adenosine triphosphate-sensitive potassium channels (Kawano et al. 2005). On the other hand, recent experiments showed that a racemic mixture of ketamine and its $\mathrm{S}-(+)$-enantiomer were capable of preconditioning isolated human myocardium in vitro, and that this effect is mediated, at least in part, by the activation of adenosine triphosphatesensitive potassium channels and stimulation of $\alpha$ - and $\beta$ adrenergic receptors (Hanouz et al. 2005).

Dexmedetomidine reduces central adrenergic outflow, thereby abolishing ketamine's cardiostimulatory effects (Levanen et al. 1995) and suppressing the stress response to surgery, leading to reduced plasma catecholamine levels (Jalonen et al. 1997). Dexmedetomidine also exhibits strong anesthetic (Ramsay and Luterman 2004) and analgesic properties (Jaakola et al. 1991). In cardiac surgery, dexmedetomidine infusion was observed to provide stable hemodynamics (Karakaya Kabukcu et al. 2011). In an animal model of hemorrhagic shock, it was suggested that the combination of ketamine with the $\alpha_{2}$-agonist medetomidine provides superior hemodynamic control and allows for a larger volume of blood loss compared with propofol-remifentanil (Brezina et al. 2010). Thus, both drugs could play distinct roles in attenuating myocardial ischemia-reperfusion injury during cardiac surgery, but either dexmedetomidine or the combination of ketamine with dexmedetomidine is probably responsible for the reduced levels of cardiac biomarkers observed in this study, rather than racemic ketamine itself.

We observed no significant differences between groups regarding the perioperative use of vasoactive medication/inotropes, the need for pacing, or other intraoperative and postoperative clinical markers of myocardial injury. In the KET-DEX group, nonsignificantly elevated incidences of hypertension and bradycardia after anesthesia induction were observed, but both conditions quickly responded to the appropriate treatment (short-term, low-dose nitroglycerine infusion and atropine, respectively). This finding is consistent with the reported effects of dexmedetomidine, in which a transient increase in vascular resistance caused by the stimulation of peripheral $\alpha_{1}$-adrenergic receptors is usually observed after administration of the anesthetic (Bhana et al. 2000). After aortic unclamping, and with intra-operative myocardial protection conferred by cold crystalloid cardioplegic solution, the initial heart rhythm is usually ventricular fibrillation. The number of required defibrillation discharges after aortic unclamping was comparable between the groups; this finding is unlikely to influence the observed differences in the levels of cardiac biomarkers. The lack of differences in clinical markers of myocardial injury between the groups can probably be explained by the low-risk profile of all of our patients. However, ketamine-dexmedetomidine anesthesia was associated with earlier extubation in the ICU. This result could be attributed to the fact that lowdose dexmedetomidine infusion was terminated 15-30 min after the patients' arrival in the ICU (low-dose sufentanil infusion was also terminated in patients who received sevoflurane-sufentanil anesthesia over the same time interval after the patients' arrival in the ICU).

Our study has several inherent limitations. The retrospective nature of our study was associated with the incomplete standardization of anesthesia protocols (i.e., wider dose ranges of anesthetic drugs for each group). Blood samples for biochemical analysis were drawn from all patients using standardized methods mandated by departmental guidelines, but not at precisely the same time intervals after aortic unclamping or patient arrival in the ICU. Furthermore, the levels of cardiac biomarkers were analyzed at only two time points, with the second occuring approximately $19 \mathrm{~h}$ after aortic unclamping, which hinders direct comparison with prospectivelly conducted studies and limits the accuracy of the AUC values. Similarly, the anti-inflammatory potential of ketamine could not be explored in sufficient detail due to 
the limited availability of the values of the appropriate laboratory markers, with the exception of the postoperative white blood cell count.

Furthermore, sufentanil and midazolam were administered in both groups. Opioid receptors are reported to play a role in cardioprotection, with the involvement of $\delta_{2}$-opioid receptors inducing cardiac tolerance to ischemia-reperfusion injury (Maslov et al. 2010). However, the dose of sufentanil (a strong $\mu$-opioid receptor agonist and a weak $\delta$-opioid receptor agonist) was markedly lower in the KET-DEX group compared with SEVO group.

Another possible limitation of the present study was the relatively small number of patients analyzed. Diabetic patients treated with sulfonylurea derivatives were not excluded. These drugs are known to block adenosine triphosphate-sensitive potassium channels, thus abolishing the cardioprotective effects of inhalational anesthetics (Lee and Chou 2003). However, the number of diabetic patients was similar in both groups, and sulfonylurea derivatives were used in only a minority of them. Furthermore, oral antidiabetic medications were discontinued on the day of surgery. Conversely, all patients were low-risk and exhibited the same type of intraoperative myocardial protection, which minimized the differences between the groups, with the exception of the anesthetics used, which could affect the postoperative levels of cardiac biomarkers. Also, patients with severe renal impairment, which could influence the elimination of cardiac biomarkers, were excluded from the present study.

In conclusion, ketamine-dexmedetomidine anesthesia during elective $\mathrm{CABG}$ resulted in lower postoperative levels of $\mathrm{cTnI}$ and CK-MB compared with sevoflurane-sufentanil anesthesia. No significant differences in clinical intraoperative and postoperative markers of myocardial injury were observed. Our results suggest that ketamine-dexmedetomidine anesthesia is a more favourable alternative to sevoflurane-sufentanil anesthesia in terms of cardioprotection in adult patients undergoing cardiac surgery. This cardioprotective effect needs to be demonstrated in randomized controlled trials and in comparisons with other widely used anesthetics (e.g., the combination of propofol with opioids, different inhalational anesthetics). In addition, cTnI levels measured $24 \mathrm{~h}$ after cardiac surgery were reported to be predictive of mortality (Croal et al. 2006), and, similarly, an elevation in CK-MB and cTnI levels within $24 \mathrm{~h}$ of CABG was shown to be associated with 1-month and 1-year mortality (Domanski et al. 2011). Additional studies investigating high-risk patients are necessary to demonstrate whether ketamine-dexmedetomidine anesthesia ultimately affects long-term outcomes after cardiac surgery.

\section{Conflict of Interest}

There is no conflict of interest.

\section{Acknowledgements}

This study was supported by the Ministry of Health of the Czech Republic through the research program MZO 00023001 ,Research on cardiovascular diseases, diabetes mellitus and transplantation of vital organs" and by the Ministry of Education of the Czech Republic through the research program MSMT 1M0510. Editorial assistance and proofreading of the manuscript were provided by PulsusEdit ${ }^{\mathrm{TM}}$ (Oakville, Ontario, Canada).

\section{References}

AANTAA R, JALONEN J: Perioperative use of alpha2-adrenoceptor agonists and the cardiac patient. Eur $J$ Anaesthesiol 23: 361-372, 2006.

BELHOMME D, PEYNET J, LOUZY M, LAUNAY JM, KITAKAZE M, MENASCHE P: Evidence for preconditioning by isoflurane in coronary artery bypass graft surgery. Circulation 100: II340-II344, 1999.

BHANA N, GOA KL, MCCLELLAN KJ: Dexmedetomidine. Drugs 59: 263-268, 2000.

BIGNAMI E, BIONDI-ZOCCAI G, LANDONI G, FOCHI O, TESTA V, SHEIBAN I, GIUNTA F, ZANGRILLO A: Volatile anesthetics reduce mortality in cardiac surgery. J Cardiothorac Vasc Anesth 23: 594-599, 2009.

BREZINA A, DRABEK T, RIHA H, SCHREIBEROVA J, HESS L: The effect of medetomidine-ketamine anesthesia on hemodynamic parameters during hemorrhagic shock in minipigs. Physiol Res 59: 703-710, 2010.

CRAVEN R: Ketamine. Anaesthesia 62 (Suppl 1): 48-53, 2007. 
CROAL BL, HILLIS GS, GIBSON PH, FAZAL MT, EL-SHAFEI H, GIBSON G, JEFFREY RR, BUCHAN KG, WEST D, CUTHBERTSON BH: Relationship between postoperative cardiac troponin I levels and outcome of cardiac surgery. Circulation 114: 1468-1475, 2006.

De HERT SG, TEN BROECKE PW, MERTENS E, VAN SOMMEREN EW, De BLIER IG, STOCKMAN BA, RODRIGUS IE: Sevoflurane but not propofol preserves myocardial function in coronary surgery patients. Anesthesiology 97: 42-49, 2002.

DE HERT SG, VAN DER LINDEN PJ, CROMHEECKE S, MEEUS R, NELIS A, VAN REETH V, TEN BROECKE PW, DE BLIER IG, STOCKMAN BA, RODRIGUS IE: Cardioprotective properties of sevoflurane in patients undergoing coronary surgery with cardiopulmonary bypass are related to the modalities of its administration. Anesthesiology 101: 299-310, 2004.

DE HERT SG, PRECKEL B, SCHLACK WS: Update on inhalational anaesthetics. Curr Opin Anaesthesiol 22: 491495, 2009.

DOMANSKI MJ, MAHAFFEY K, HASSELBLAD V, BRENER SJ, SMITH PK, HILLIS G, ENGOREN M, ALEXANDER JH, LEVY JH, CHAITMAN BR, BRODERICK S, MACK MJ, PIEPER KS, FARKOUH ME: Association of myocardial enzyme elevation and survival following coronary artery bypass graft surgery. JAMA 305: 585-591, 2011.

EASLEY RB, TOBIAS JD: Pro: dexmedetomidine should be used for infants and children undergoing cardiac surgery. J Cardiothorac Vasc Anesth 22: 147-151, 2008.

FLIER S, POST J, CONCEPCION AN, KAPPEN TH, KALKMAN CJ, BUHRE WF: Influence of propofol-opioid vs isoflurane-opioid anaesthesia on postoperative troponin release in patients undergoing coronary artery bypass grafting. Br J Anaesth 105: 122-130, 2010.

FRASSDORF J, BOROWSKI A, EBEL D, FEINDT P, HERMES M, MEEMANN T, WEBER R, MULLENHEIM J, WEBER NC, PRECKEL B, SCHLACK W: Impact of preconditioning protocol on anesthetic-induced cardioprotection in patients having coronary artery bypass surgery. J Thorac Cardiovasc Surg 137: 1436-1442, 2009.

HANOUZ JL, ZHU L, PERSEHAYE E, MASSETTI M, BABATASI G, KHAYAT A, DUCOURET P, PLAUD B, GERARD JL: Ketamine preconditions isolated human right atrial myocardium: roles of adenosine triphosphate-sensitive potassium channels and adrenoceptors. Anesthesiology 102: 1190-1196, 2005.

HUDETZ JA, PATTERSON KM, IQBAL Z, GANDHI SD, BYRNE AJ, HUDETZ AG, WARLTIER DC, PAGEL PS: Ketamine attenuates delirium after cardiac surgery with cardiopulmonary bypass. $J$ Cardiothorac Vasc Anesth 23: 651-657, 2009.

JAAKOLA ML, SALONEN M, LEHTINEN R, SCHEININ H: The analgesic action of dexmedetomidine - a novel alpha 2-adrenoceptor agonist - in healthy volunteers. Pain 46: 281-285, 1991.

JALONEN J, HYNYNEN M, KUITUNEN A, HEIKKILA H, PERTTILA J, SALMENPERA M, VALTONEN M, AANTAA R, KALLIO A: Dexmedetomidine as an anesthetic adjunct in coronary artery bypass grafting. Anesthesiology 86: 331-345, 1997.

KARAKAYA KABUKCU H, SAHIN N, TEMEL Y, AYDOGDU TITIZ T: Hemodynamics in coronary artery bypass surgery: effects of intraoperative dexmedetomidine administration. Anaesthesist 60: 427-431, 2011.

KAWANO T, OSHITA S, TAKAHASHI A, TSUTSUMI Y, TANAKA K, TOMIYAMA Y, KITAHATA H, NAKAYA Y: Molecular mechanisms underlying ketamine-mediated inhibition of sarcolemmal adenosine triphosphate-sensitive potassium channels. Anesthesiology 102: 93-101, 2005.

LANDONI G, BIONDI-ZOCCAI GG, ZANGRILLO A, BIGNAMI E, D'AVOLIO S, MARCHETTI C, CALABRO MG, FOCHI O, GUARRACINO F, TRITAPEPE L, DE HERT S, TORRI G: Desflurane and sevoflurane in cardiac surgery: a meta-analysis of randomized clinical trials. J Cardiothorac Vasc Anesth 21: 502-511, 2007.

LANDONI G, FOCHI O, TRITAPEPE L, GUARRACINO F, BELLONI I, BIGNAMI E, ZANGRILLO A: Cardiac protection by volatile anesthetics. A review. Minerva Anestesiol 75: 269-273, 2009.

LEE TM, CHOU TF: Impairment of myocardial protection in type 2 diabetic patients. J Clin Endocrinol Metab 88: 531-537, 2003.

LEVANEN J, MAKELA ML, SCHEININ H: Dexmedetomidine premedication attenuates ketamine-induced cardiostimulatory effects and postanesthetic delirium. Anesthesiology 82: 1117-1125, 1995. 
MASLOV LN, LISHMANOV YB, OELTGEN PR, BARZAKH EI, KRYLATOV AV, NARYZHNAYA NV, PEI JM, BROWN SA: Comparative analysis of the cardioprotective properties of opioid receptor agonists in a rat model of myocardial infarction. Acad Emerg Med 17: 1239-1246, 2010.

MULLENHEIM J, FRASSDORF J, PRECKEL B, THAMER V, SCHLACK W: Ketamine, but not S(+)-ketamine, blocks ischemic preconditioning in rabbit hearts in vivo. Anesthesiology 94: 630-636, 2001.

MURPHY PG, MYERS DS, DAVIES MJ, WEBSTER NR, JONES JG: The antioxidant potential of propofol (2,6diisopropylphenol). Br J Anaesth 68: 613-618, 1992.

NEUHAUSER C, PREISS V, FEURER MK, MULLER M, SCHOLZ S, KWAPISZ M, MOGK M, WELTERS ID: Comparison of S-(+)-ketamine- with sufentanil-based anaesthesia for elective coronary artery bypass graft surgery: effect on troponin T levels. Br J Anaesth 100: 765-771, 2008.

RAMSAY MA, LUTERMAN DL: Dexmedetomidine as a total intravenous anesthetic agent. Anesthesiology 101: $787-$ $790,2004$.

WELTERS ID, FEURER MK, PREISS V, MULLER M, SCHOLZ S, KWAPISZ M, MOGK M, NEUHAUSER C: Continuous S-(+)-ketamine administration during elective coronary artery bypass graft surgery attenuates proinflammatory cytokine response during and after cardiopulmonary bypass. Br J Anaesth 106: 172-179, 2011.

XIA Z, HUANG Z, ANSLEY DM: Large-dose propofol during cardiopulmonary bypass decreases biochemical markers of myocardial injury in coronary surgery patients: a comparison with isoflurane. Anesth Analg 103: 527-532, 2006. 